\title{
Spigelian hernia: current approaches to surgical treatment-a review
}

\author{
I. Hanzalova ${ }^{1} \cdot$ M. Schäfer $^{1} \cdot$ N. Demartines ${ }^{1} \cdot$ D. Clerc $^{1}$ \\ Received: 8 May 2021 / Accepted: 5 September 2021 / Published online: 19 October 2021 \\ (c) The Author(s) 2021
}

\begin{abstract}
Background Spigelian hernias $(\mathrm{SpH})$ belong to the group of eponymous abdominal wall hernias. Major reasons for diagnostic difficulties are its low incidence reaching maximum $2 \%$ of abdominal wall hernias, a specific anatomical localization with intact external oblique aponeurosis covering the hernia sac and non-constant clinical presentation.

Methods A literature review was completed to summarize current knowledge on surgical treatment options and results.

Results $\mathrm{SpH}$ presents a high incarceration risk and therefore should be operated upon even if the patient is asymptomatic. Both laparoscopic and open repair approaches are validated by current guidelines with lesser postoperative complications and shorter hospital stay in favour of minimally invasive surgery, regardless of the technique used. Overall recurrence rate is very low.

Conclusion All diagnosed SpH should be planned for elective operation to prevent strangulated hernia and, therefore emergency surgery. Both open and laparoscopic $\mathrm{SpH}$ treatment can be safely performed, depending on surgeon's experience. In most cases, a mesh repair is generally advised.
\end{abstract}

Keywords Hernia surgery $\cdot$ Spigelian hernia $\cdot$ Review $\cdot$ Minimally invasive surgery $\cdot$ Surgical anatomy

$\begin{array}{ll}\text { Abbreviations } \\ \text { SpH } & \text { Spigelian hernia } \\ \text { US } & \text { Ultra-sonography } \\ \text { CT } & \text { Computed tomography } \\ \text { EHS } & \text { European Hernia Society } \\ \text { AHS } & \text { Americas Hernia Societies } \\ \text { IPOM } & \text { IntraPeritoneal onlay mesh } \\ \text { TEP } & \text { Totally extraperitoneal } \\ \text { TAPP } & \text { TransAbdominal PrePeritoneal } \\ \text { SIL } & \text { Single incision laparoscopy }\end{array}$

\section{Introduction}

A Spigelian hernia $(\mathrm{SpH})$ is a rare type of ventral hernia, principally acquired. Its name originates from a Flemish anatomist and physician, Adriann van den Spieghel (1578-1625), who introduced several new anatomic descriptions. Particularly, he described the well-known linea semilunaris, originally named as the linea semilunaris spigelii

M. Schäfer

markus.schafer@chuv.ch

1 Department of Visceral Surgery, Lausanne University Hospital CHUV, Bugnon 46, 1011 Lausanne, Switzerland
[1]. However, the first description of $\mathrm{SpH}$ itself occurred about one century later by the Bohemian anatomist and surgeon Josef Klinkosh, describing a ventral hernia occurring at the level of the "linea spigelii", therefore named Spigelian Hernia. [2]. The particular anatomy of $\mathrm{SpH}$ contributes to the choice of the most appropriate surgical therapy, especially when it comes to minimally invasive techniques. The main objective of this review is to summarize the current evidence on the best surgical approaches for $\mathrm{SpH}$, in both elective and emergency situations.

\section{Methods}

A literature review on $\mathrm{SpH}$ was performed by two authors (IH, DC) using Medline, Web of Science Google scholar for English and French sources. All possible variants of Spiegel's name spelling ("Spiegel”, "Spigelian", "Spiegelian", "Spigel") as well as both descriptive names"Spontaneous lateral ventral hernia" and "Hernia of the semilunar line" were used. All retained studies had a special focus on surgical anatomy, surgical treatment and outcomes. Guidelines of relevant associations, such as the European hernia society (EHS) and Americas Hernia Societies (AHS) 
were also considered. Emphasis was put on articles published within the past 10 years.

\section{Surgical anatomy}

The $\mathrm{SpH}$ orifice is localised at the Spigelian point, Spigelian fascia or interchangeably called Spigelian aponeurosis, which lies laterally to the rectus abdominis muscle and medially to the semilunar line. The term semilunar line refers to the edge of the transverse and internal oblique muscles aponeuroses, respectively [3]. Hence, the semilunar line represents the border between the aponeurosis and the transverse abdominal muscle extending from the cartilage of the ninth rib to the pubic tubercle. Given a transition between Spigelian fascia and the posterior sheath of the rectus abdominis which varies above and below the arcuate line, the most common localisation of the $\mathrm{SpH}$ lies within an imaginary $6 \mathrm{~cm}$ wide band superior to the interspinous line, the so-called Spigelian belt [4] (Fig. 1). This region carries the greatest abdominal circumference and thus highest intraabdominal pressure. Consequently, the Spigelian fascia extends to its largest size that is prone to hernia development. In a recent series, Spigelian hernias located cranially to the arcuate line were reported in more than $10 \%$ of patients [5]. Furthermore, the term "Low Spigelian hernia" qualifies a $\mathrm{SpH}$ subtype located caudally to the inferior epigastric artery, within the Hesselbach's triangle, first

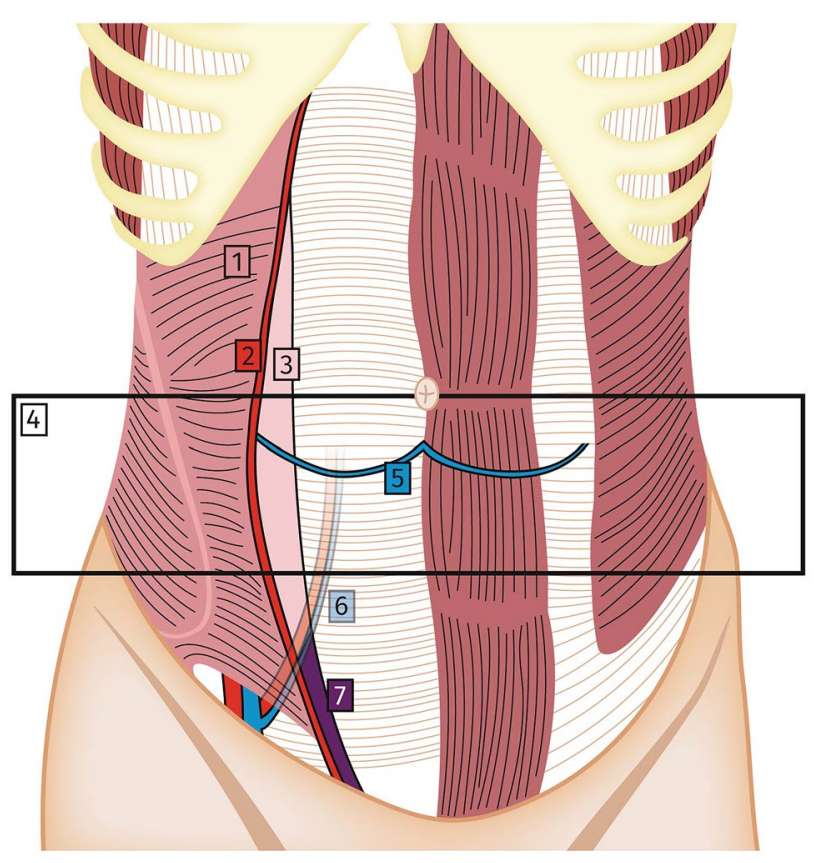

Fig. 1 Surgical anatomy of the abdominal wall. Abdominal wall anatomy, coronal view. (1)Transverse abdominal muscle, (2) Semilunar line, (3) Spigelian fascia, (4) Spigelian hernia belt, (5) Arcuate line, (6) inferior epigastric artery and vein, (7) Low Spigelian hernia area introduced by Spangen [4], and found in about $8 \%$ of groin hernia repairs in the Klimopoulos series [6].

On the axial plane, the hernia sac tends to spread laterally to the interstitial zone between internal and external oblique muscles. In the majority of cases, $\mathrm{SpH}$ develops without penetrating the intact External oblique aponeurosis. This observation was confirmed in $90 \%$ of $\mathrm{SpH}$ in a French series of 51 patients [7]. The $\mathrm{SpH}$ specific anatomic location, with a rather small hernia orifice, usually non-exceeding $2 \mathrm{~cm}$ in diameter, within a rigid Spigelian aponeurosis and an interoblique hernia sac development make this condition difficult to diagnose with a particular tendency for incarceration (Fig. 2).

\section{Epidemiology}

The true incidence of $\mathrm{SpH}$ in the general population remains unknown as many patients will never have symptoms that lead to the diagnostics. Previous reports suggests an incidence of $1-2 \%$ of all ventral hernias $[5,8]$. In one large ultrasonography study of 785 anterior abdominal wall hernias, $1.4 \% \mathrm{SpH}$ were diagnosed [9]. A recent study, searching for occult ventral hernia during general laparoscopy procedures in more than 200 patients, a Spigelian fascia defect was identified in $2 \%$ of asymptomatic patients [8]. According to the largest published series, $\mathrm{SpH}$ mainly affects the adult population, with a median age of 65 years at diagnosis $[5,10] . \mathrm{SpH}$ is more frequent in female, with a reported female to male ratio of $2: 1$ [5, 11, 12]. Previous pregnancies and higher intraabdominal pressure during delivery have been assumed as predisposing factors [13, 14]. A "natural progression" of $\mathrm{SpH}$ in adults was recently supported by the finding that younger patients presented smaller Spigelian fascia defects with only preperitoneal content in most cases,

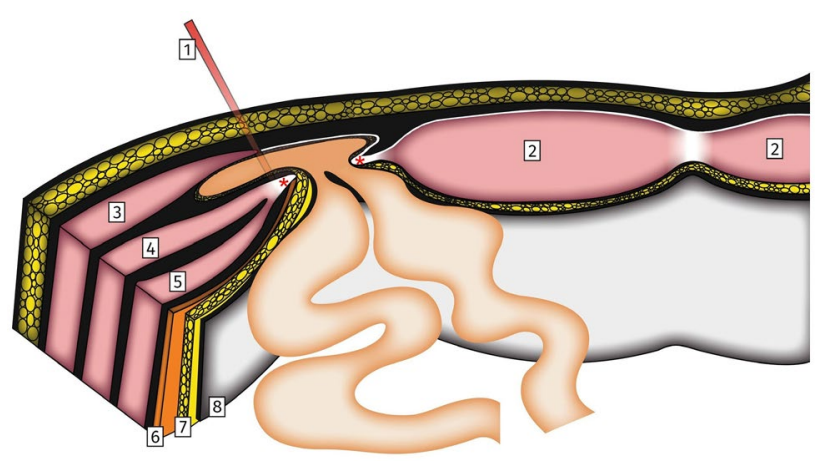

Fig. 2 Spigelian Hernia surgical anatomy. Drawing depicting a leftsided Spigelian hernia, axial view. Note the Spigelian hernia penetrating the Spigelian fascia (red asterisks) with an intact External oblique aponeurosis. (1) Semilunar line, (2) Rectus abdominis muscle, (3) External oblique muscle with aponeurosis, (4) Internal oblique muscle, (5) Transverse abdominal muscle, (6) Fascia transversalis, (7) Pre-peritoneal fat, (8) Peritoneum 
in contrast to elderly patients who were more prone to present bigger hernias with peritoneal content at diagnosis [5]. $\mathrm{SpH}$ seems slightly predominant on the left side, based on a systematic review comprising more than $200 \mathrm{SpH}$ [15], but underlying reasons are yet unknown.

The most important epidemiologic feature lies in the risk of incarceration with need for emergency surgery, reaching up to $24 \%$ of all $\mathrm{SpH}$ [4], and confirmed with contemporary data of $17 \%[5,10]$. This is mostly explained by a small and tight defect in the Spigelian fascia in comparison to the hernia content $[5,10,16]$. SpH carries therefore a much higher risk of incarceration compared to other ventral hernias. For instance, a rate of only $4 \% 5$-year strangulation risk during "watch and wait" observation period of umbilical hernias is reported [17]. For inguinal hernia, the strangulation risk varies between 0.27 and $2.5 \%$ depending on the length of follow-up [18].

\section{Clinical presentation and differential diagnosis}

The clinical presentation is frequently ambiguous and its diagnosis remains difficult. Patients most frequently experience intermittent pain, and swelling sensation in the lower abdomen [15]. According to the experience of Larson et al. [10], two-thirds of the patients describe clinical symptoms without any clinical findings. Webber et al. suggested the development of $\mathrm{SpH}$ in two stages: firstly, small $\mathrm{SpH}$ without any peritoneal component, typically occurs in younger patients complaining only of intermittent pain, without palpable mass; and secondly, a larger $\mathrm{SpH}$ develops with a palpable hernia sac [5]. Patients presenting evocative symptoms without any clinically palpable lump can be diagnosed having an occult $\mathrm{SpH}$. Most frequently, incarcerated structures are small bowel, greater omentum and sigmoid colon [5]. Incarceration of unusual hernia content was reported in several case reports, such as Meckel's diverticulum, stomach, ovary or urinary bladder [39-41].

Low $\mathrm{SpH}$ can be mistaken with inguinal hernia, and final diagnosis is only confirmed intraoperatively [5, 6]. A digital palpation of the patient's inguinal canal with Valsalva manoeuvre in a standing position has been proposed to distinguish between low $\mathrm{SpH}$ and direct inguinal hernia [6]. Co-existence of low $\mathrm{SpH}$ and direct inguinal hernia has been reported, most likely due to concomitant weakness of the Spigelian fascia around insertion of the rectus abdominis [19].

Differential diagnosis of a palpable mass in the typical region of $\mathrm{SpH}$, includes lipoma [5], hematoma of rectus abdominis muscle or any abdominal solid tumour. Pain in the left inguinal fossa without palpable lump, can be confused with all other causes of left-sided abdominal pain, such as acute sigmoid diverticulitis for instance [20].

\section{Classification}

$\mathrm{SpH}$ is a subgroup of primary ventral hernias, and the EHS classification should be applied for classification purposes [21]. The most commonly reported hernia defect size is up to $2 \mathrm{~cm}$ diameter, which corresponds to the small hernia group. Medium and large $\mathrm{SpH}$ are those with a defect of $>2 \mathrm{~cm}$ and $>4 \mathrm{~cm}$, respectively. A distinction between $\mathrm{SpH}$ with and without peritoneal components was recently described, which has an impact on the choice of the appropriate surgical approach [5]. Low $\mathrm{SpH}$ can be classified in the Nyhus (type Ib) or Gilbert (type 5) inguinal hernia classifications [6].

\section{Predisposing factors}

Similar to other ventral hernias, factors contributing to high intraabdominal pressure, such as chronic obstructive pulmonary disease, chronic cough and obesity are found regularly among patients with $\mathrm{SpH}$. A possible contribution of the pneumoperitoneum during a laparoscopic procedure in development of the $\mathrm{SpH}$ through a pre-existing weakness in the Spigelian fascia has been hypothesized by Slakey et al., describing one case of the incarcerated Spigelian hernia following laparoscopic living donor nephrectomy [22]. SpH are often diagnosed in patients presenting another type of the ventral hernia, either current or previous [15, 23]. Continuous ambulatory peritoneal dialysis has also been reported as a risk factor [11, 24].

\section{Diagnostic workup}

$\mathrm{SpH}$ remains a clinical diagnosis, but equivocal clinical features are common. Imaging techniques, such as abdominal wall ultrasonography (US) or computed tomography (CT) scan are usually performed in case of doubtful diagnosis. If doubts persist despite imaging, a diagnostic laparoscopy is considered. In the largest series published to date, up to $20 \%$ of diagnosis was confirmed by imaging method, due to unclear physical examination [10]. Several studies suggest that abdominal wall ultrasonography is a conclusive imaging method in $\mathrm{SpH}$, with a sensitivity of 83-90\% [24-26]. The benefit of CT scan imaging lies in the possibility to visualise the hernia content supplementary to the visualization of the hernia defect (Fig. 3). In case of an occult $\mathrm{SpH}$, a diagnosis confirmation with imaging is recommended [25]. Diagnostic laparoscopy is reserved for patients with persisting symptoms and ambiguous findings on US and CT imaging [27, 28]. 


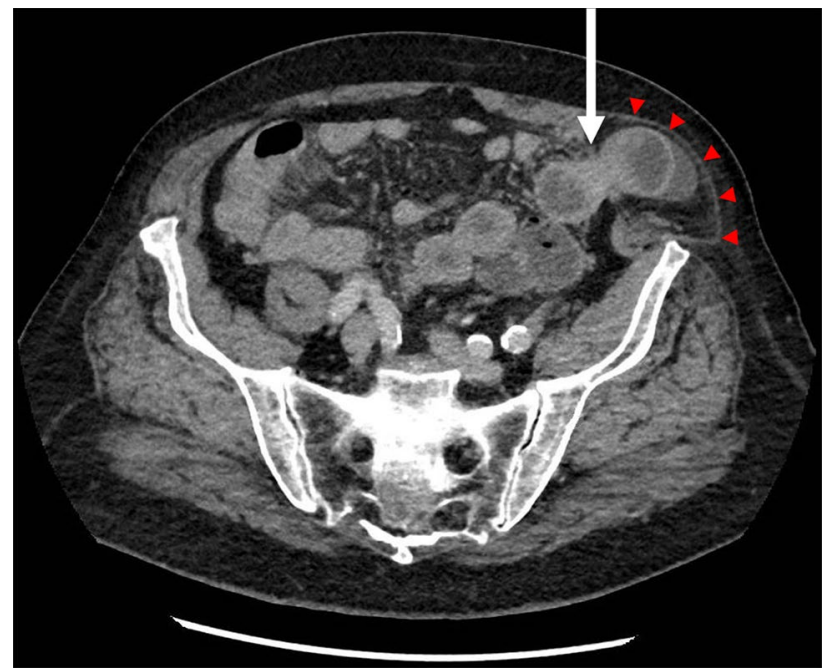

Fig. 3 Spigelian Hernia on CT scan. Abdominal CT-scan depicting left-sided incarcerated Spigelian Hernia with small bowel content (arrow). Note the intact External oblique aponeurosis (arrowheads)

\section{Treatment options}

The significant risk of incarceration taken into account, all $\mathrm{SpH}$ should be repaired surgically [5, 10, 29]. According to the recent EHS guidelines [28], there are no definitive preferences between open and minimally invasive approaches and the choice is at the discretion of the operating surgeon. Furthermore, a mesh repair is recommended regardless of the approach used. Repair with direct suture can be safely performed for $\mathrm{SpH}$ with small defects. Overall recurrence rate is very low, especially after mesh repair $[23,30]$. In cases of intraperitoneal mesh placement, the use of composite or covered mesh is advocated, to decrease post-operative adhesions [31]. As for all ventral hernia, a mesh overlap exceeding the hernia neck more than $5 \mathrm{~cm}$ is mandatory. Closure of the $\mathrm{SpH}$ defect before mesh insertion is debated. While some authors consider it unnecessary [31], this issue is not addressed in the EHS position statement [28]. For most mesh repairs and regardless of the technique used, a polypropylene mesh can be inserted, except in cases of intra-abdominal mesh placement, where composite mesh should be considered [23, 34].

The most frequent early complications described are seromas, hematomas, and wound infections. While overall postoperative complications are rather rare [15, 29], they were even less frequent in case of laparoscopic repair, with $2.3 \%$ of post-operative complications reported by Skouras et al. [30], compared to $18 \%$ in open cases [11]. Both studies reported a rather small number of patients and only six patients represented the relatively high rate of complications.

\section{Open vs. laparoscopy}

First laparoscopic operation for $\mathrm{SpH}$ was performed in 1992 [32]. Nowadays, minimally invasive techniques are considered and applied in all aspects of hernia surgery, aiming to reduce early postoperative morbidity, length of hospitalisation and returning earlier to normal activities. This was confirmed in cases of $\mathrm{SpH}$ in several series [11, 23]. Intraperitoneal laparoscopic approach gives the advantage to easily examine the entire abdominal wall while a standard open repair might require a longer incision to explore the abdominal wall, especially when the $\mathrm{SpH}$ is not palpable [31].

Despite evolution in minimally invasive techniques, there are still some persistent benefits to the open repair. Related to $\mathrm{SpH}$ size, a small preperitoneal $\mathrm{SpH}$ with no peritoneal sac and content, can be difficult to detect by laparoscopy. On the other hand, voluminous $\mathrm{SpH}$ with awaited substantial abdominal wall repair is probably best treated with an open approach [5]. Furthermore, treatment under loco-regional anaesthesia is possible only for open repair [11]. Anterior hernioplasty with pre-peritoneal sublay mesh under local anaesthesia was reported as a successful outpatient procedure without any long-term recurrences [33].

Results of some of the largest series on $\mathrm{SpH}$ repair published to date are summarized in Table 1.

\section{The choice of the laparoscopic technique}

Similarly to the treatment of other ventral or inguinal hernias, minimally invasive techniques of IPOM (IntraPeritoneal Onlay Mesh), TEP (Totally ExtraPeritoneal) and TAPP (TransAbdominal PrePeritoneal) can be used for the $\mathrm{SpH}$ repair. There is currently no solid recommendation in favour of one of those methods but some benefits and possible limitations have been described. The only existing prospective study [31] comparing TEP versus IPOM repair demonstrated excellent results with no complications and recurrences at 4 years, for both methods. The TEP approach nevertheless reported to double the overall cost compared to IPOM, mostly due to the price of the balloon dissector.

The TEP repair is preferred by some authors as it does not require access to the peritoneal cavity and decreases the risk of intra-abdominal adhesions [27]. Moreno-Egea et al. proposed a TEP repair in patients with reducible low $\mathrm{SpH}$ of rather small size [31]. TEP techniques requires more technical skills with a longer learning curve compared to other laparoscopic techniques [31]. Moreover, the TEP approach can be used only if the $\mathrm{SpH}$ is located below the arcuate line [5]. The possible benefit from a TEP repair is the ability to explore and treat a concomitant direct inguinal hernia [19].

Advantages of an IPOM procedure, and also to the TAPP method, is the possibility to explore the whole abdominal cavity $[23,30,34]$. Both methods have also 
Table 1 Relevant published series on Spigelian hernia surgical treatment

\begin{tabular}{|c|c|c|c|c|c|c|c|c|c|}
\hline Year & Design & Author & Patients & Open & MIS & LOS, days & Morbidity, $n(\%)$ & Recurrence, $n(\%)$ & $\begin{array}{l}\text { Follow- } \\
\text { up, } \\
\text { months }\end{array}$ \\
\hline 2002 & $\mathrm{RCT}$ & Moreno-Egea et al & 22 & 11 & $11\left(8 * ; 3^{* *}\right)$ & $\begin{array}{l}\text { Open: } 3 \\
\text { MIS: } 1^{*} ; 1,4^{* *}\end{array}$ & $\begin{array}{l}\text { Open: } 4(18 \%) \\
\text { MIS: } 0\end{array}$ & 0 & 40 \\
\hline 2002 & Retrospective & Larson et al & 76 & 75 & $1 * *$ & N/A & $8(11 \%)$ & $\begin{array}{l}\text { Open:3 (4\%) } \\
\text { MIS: } 0\end{array}$ & 96 \\
\hline 2006 & Prospective & Palanivelu et al & 8 & 0 & $8 * * *$ & 1,2 & 0 & 0 & 41 \\
\hline 2006 & Prospective & Malazgirt et al & 34 & 31 & $3 * * *$ & 4,1 & $6(18 \%)$ & N/A & 30 \\
\hline 2010 & Retrospective & Nirmal et al & 6 & 0 & $6 * * *$ & 1.2 & $1(17 \%)$ & 0 & 6 \\
\hline 2012 & Retrospective & Perrakis et al & 16 & 15 & $1 * *$ & $\begin{array}{l}\text { Open: } 3.5 \\
\text { MIS: } 1{ }^{* *}\end{array}$ & $2(13 \%)$ & 0 & 98 \\
\hline 2012 & Prospective & Zuvela et al & 8 & 8 & 0 & $0^{\Delta}$ & 0 & 0 & 23,5 \\
\hline 2014 & $\mathrm{RCT}$ & Moreno-Egea et al & 16 & 0 & $16(7 * ; 9 * *)$ & 1 & 0 & 0 & 48 \\
\hline 2017 & Retrospective & Webber et al & 101 & 68 & 33 & N/A & N/A & N/A & N/A \\
\hline 2018 & Retrospective & Rankin et al & 33 & 27 & $6^{* * *}$ & $\begin{array}{l}\text { Elective: } 1.6 \\
\text { Emergency: } 5.6\end{array}$ & $7(21 \%)$ & 0 & 32 \\
\hline 2020 & Retrospective & $\begin{array}{l}\text { Ruiz de la Hermosa } \\
\text { et al }\end{array}$ & 39 & 30 & $9 * *$ & $\begin{array}{l}\text { Elective: } 2.6 \\
\text { Emergency: } 4\end{array}$ & $2(5 \%)$ & $2(5 \%)$ & N/A \\
\hline
\end{tabular}

RCT Randomized controlled trial, LOS Length of hospital stay, MIS Minimally Invasive Surgery.

*TEP_Totally ExtraPeritoneal

**IPOM-IntraPeritoneal Onlay Mesh

***TAPP—TransAbdominal PrePeritoneal, ${ }^{\Delta}$ Outpatient procedures

been described in the emergency setting with incarcerated hernia content. The IPOM technique is considered to be the easiest to learn and to perform safely even for surgeons not specialized in abdominal wall hernia surgery [31].

The main limitation of the IPOM is the risk of the nerve entrapment or hematoma as a result of tack or staple application. As a possible solution, a fibrin sealant instead of tacks has been proposed [35]. However, no published data on IPOM for $\mathrm{SpH}$ described tacks or intraperitoneal mesh complication [31]. According to Moreno-Egea et al., a $\mathrm{SpH}$ size of $>3 \mathrm{~cm}$, bilateral hernia and irreducible content are factors in favour of an intraperitoneal technique.

One possible limitation linked to the TAPP method, highlighted by Moreno-Egea et al. [31], is the potential difficulty of the closure of the peritoneal flap, due to a thinner and fragile peritoneum in this location.

Single-incision laparoscopic totally extra peritoneal (SIL-TEP) repair of $\mathrm{SpH}$ was reported as an alternative technical approach. The main advantage highlighted was the cost reduction thanks to the telescopic extra peritoneal dissection, instead of standard balloon dissector used for the TEP technique. The authors described no recurrence after a short follow-up of 9 months [19].

Case reports on robotic $\mathrm{SpH}$ repair have been published recently, with promising preliminary data $[36,37]$.

\section{Emergency surgery}

There is a relatively small body of literature specific to the emergency surgery of $\mathrm{SpH}$. Emergency $\mathrm{SpH}$ cases were described in case reports. In the Larson et al. series, describing eight patients for emergency clinical presentation, seven had incarcerated tissue needing a resection [10]. In this particular context, the decision to perform a mesh repair versus direct suture must be taken after considering the risk of wound infection.

\section{Conclusion}

$\mathrm{SpH}$ incidence is currently unknown, but number of cases reported has recently grown with the widely use of crosssectional imaging techniques. $\mathrm{SpH}$ remains a diagnostic challenge, due to the specific anatomic localisation under the external oblique aponeurosis. Moreover, $\mathrm{SpH}$ are significantly at higher risk of incarceration compared to other type of abdominal wall hernias. Consequently, even asymptomatic $\mathrm{SpH}$ should be considered for elective repair. Nowadays, and similarly to other ventral hernia, $\mathrm{SpH}$ can be treated with minimally invasive techniques, even in the emergency setting. There are however, no clear guidelines 
in favour of one specific laparoscopic technique over another with generally low morbidity and recurrence rate, based on several series of patients. An open approach remains a valid option for large hernias or in case of emergency surgery with expected bowel resection. At present, none of the existing mini-invasive approaches showed superiority, apart some anatomic limitations with the TEP approach. Intraabdominal laparoscopic approaches are easier to learn and perform with better overview of the abdominal cavity. Regardless of the technique employed, a mesh repair is recommended. Nevertheless, a non-mesh repair remains a reasonable alternative in small hernias.

The evidence regarding optimal management of $\mathrm{SpH}$ is still based on indirect evidence from studies with a rather limited number of patients. As a rather rare ventral hernia, further evidence on all aspects of $\mathrm{SpH}$ might arise from large international registry-based data.

Acknowledgements The authors thank Ing. Petr Jarušek for electronic editing of the anatomy figures

Author contributions Conception and design: IH, DC. Literature review: IH, DC. Artwork crafting: IH. Drafting the manuscript: IH, DC. Review and editing: all authors. The final manuscript was approved by all authors.

Funding Open Access funding provided by Université de Lausanne. None.

Availability of data and material Not applicable.

Code availability Not applicable.

\section{Declarations}

Conflict of interest The authors declare that they have no competing interest.

Ethical approval All procedures performed in studies involving human participants were in accordance with the ethical standards of the institutional and national research committee and with the 1964 Helsinki Declaration and its later amendments or comparable ethical standards.

Human and animal rights This article does not contain any studies with human participants or animals performed by any of the authors.

Informed consent Formal written consent was sought from patients prior to surgery (concerning the anonymous use of radiological images in the present publication) to be included in a secure database for research and publication purposes. Copy of the written consent available on request.

Open Access This article is licensed under a Creative Commons Attribution 4.0 International License, which permits use, sharing, adaptation, distribution and reproduction in any medium or format, as long as you give appropriate credit to the original author(s) and the source, provide a link to the Creative Commons licence, and indicate if changes were made. The images or other third party material in this article are included in the article's Creative Commons licence, unless indicated otherwise in a credit line to the material. If material is not included in the article's Creative Commons licence and your intended use is not permitted by statutory regulation or exceeds the permitted use, you will need to obtain permission directly from the copyright holder. To view a copy of this licence, visit http://creativecommons.org/licenses/by/4.0/.

\section{References}

1. van den Spiegel A (1627) De humani corporis fabrica libri decem. Evangelista Deuchinus, Venice

2. Klinkosh JT (1764) Divisionem herniarum novamgue hernias ventralis specimen proponit. Dissertationum Medicorum, p 184

3. Ghosh SK, Sharma S, Biswas S, Chakraborty S (2014) Adriaan van den Spiegel (1578-1625): anatomist, physician, and botanist: a Spiegel as an Anatomist. Clin Anat 27:952-957. https://doi.org/ 10.1002/ca.22414

4. Spangen L (1989) Spigelian hernia. World J Surg 13:573-580. https://doi.org/10.1007/BF01658873

5. Webber V, Low C, Skipworth RJE et al (2017) Contemporary thoughts on the management of Spigelian hernia. Hernia. https:// doi.org/10.1007/s10029-017-1579-x

6. Klimopoulos S, Kounoudes C, Validakis A, Galanis G (2001) Low spigelian hernias: experience of 26 consecutive cases in 24 patients. Eur J Surg. https://doi.org/10.1080/110241501753171 272

7. Guivarch M, Boche O, Scherrer A, Roullet-Audy JC (2004) Hernies ventrales antérolatérales dites de Spiegel. 51 cas. Bull Acad Natl Med. https://doi.org/10.1016/s0001-4079(19)33694-5

8. Paajanen H, Ojala S, Virkkunen A (2006) Incidence of occult inguinal and spigelian hernias during laparoscopy of other reasons. Surgery 140:9-12. https://doi.org/10.1016/j.surg.2006.01. 005

9. Samokształceniowe Koło Ultrasonografii przy Zakładzie Genetyki i Patomorfologii PUM w Szczecinie, Smereczyński A, Kołaczyk $\mathrm{K}$ et al (2012) Sonographic imaging of Spigelian hernias. J Ultrason 12:269-275. https://doi.org/10.15557/JoU.2012.0012

10. Larson DW, Farley DR (2002) Spigelian hernias: Repair and outcome for 81 patients. World J Surg 26(10):1277-1281. https://doi. org/10.1007/s00268-002-6605-0

11. Malazgirt Z, Topgul K, Sokmen S et al (2006) Spigelian hernias: a prospective analysis of baseline parameters and surgical outcome of 34 consecutive patients. Hernia. https://doi.org/10.1007/ s10029-006-0103-5

12. Patle NM, Tantia O, Sasmal PK et al (2010) Laparoscopic repair of spigelian hernia: our experience. J Laparoendosc Adv Surg Tech. https://doi.org/10.1089/lap.2009.0314

13. Skandalakis PN, Zoras O, Skandalakis JE, Mirilas P (2006) Spigelian hernia: Surgical anatomy, embryology, and technique of repair. Am Surg 72(1):42-48

14. Montes IS, Deysine M (2003) Spigelian and other uncommon hernia repairs. Surg Clin North Am 83(5):1235-1253. https://doi. org/10.1016/S0039-6109(03)00130-0

15. Barnes TG, McWhinnie DL (2016) Laparoscopic spigelian hernia repair: a systematic review. Surg Laparosc Endosc Percutan Tech 26:265-270. https://doi.org/10.1097/SLE.0000000000000286

16. Mittal T, Kumar V, Khullar R, Sharma A, Soni V, Baijal M, Chowbey PK (2008) Diagnosis and management of Spigelian hernia: A review of literature and our experience. J Minim Access Surg 4(4):95-98. https://doi.org/10.4103/0972-9941.45204

17. Kokotovic D, Sjølander H, Gögenur I, Helgstrand F (2016) Watchful waiting as a treatment strategy for patients with a ventral hernia appears to be safe. Hernia. https://doi.org/10.1007/ s10029-016-1464-z 
18. Mizrahi H, Parker MC (2012) Management of asymptomatic inguinal hernia: A systematic review of the evidence. Arch Surg 147(3):277-281. https://doi.org/10.1001/archsurg.2011.914

19. Tran H, Tran K, Zajkowska $M$ et al (2015) Single-incision laparoscopic repair of spigelian hernia. JSLS J Soc Laparoendosc Surg 19(e2015):001644. https://doi.org/10.4293/JSLS.2015.001644

20. Alaoui Lamrani Y, Souiki T, Alami B et al (2014) Hernie de Spiegel: Quand l'imagerie sauve la clinique. J Africain d'HepatoGastroenterologie. https://doi.org/10.1007/s12157-014-0523-2

21. Muysoms FE, Miserez M, Berrevoet F et al (2009) Classification of primary and incisional abdominal wall hernias. Hernia. https:// doi.org/10.1007/s10029-009-0518-x

22. Slakey DR, Teplitsky S, Cheng SS (2002) Incarcerated Spigelian hernia following laparoscopic living-donor nephrectomy. J Soc Laparoendosc Surg (JSLS) 6(3):217-219

23. Moreno-Egea A, Carrasco L, Girela E et al (2002) Open vs laparoscopic repair of spigelian hernia: a prospective randomized trial. Arch Surg. https://doi.org/10.1001/archsurg.137.11.1266

24. Vos DI, Scheltinga MRM (2004) Incidence and outcome of surgical repair of spigelian hernia. Br J Surg 91:640-644. https://doi. org/10.1002/bjs.4524

25. Light D, Chattopadhyay D, Bawa S (2013) Radiological and clinical examination in the diagnosis of Spigelian hernias. Ann R Coll Surg Engl 95:98-100. https://doi.org/10.1308/003588413X13511 609957092

26. Noomene R, Bouhafa A, Ben MA et al (2014) Hernies de Spiegel. Press, Medicale

27. Mederos R, Lamas JR, Alvarado J et al (2017) Laparoscopic diagnosis and repair of Spigelian hernia: a case report and literature review. Int J Surg Case Rep 31:184-187. https://doi.org/10.1016/j. ijscr.2017.01.043

28. Henriksen NA, Kaufmann R, Simons MP et al (2020) EHS and AHS guidelines for treatment of primary ventral hernias in rare locations or special circumstances. BJS Open 4:342-353. https:// doi.org/10.1002/bjs5.50252

29. Perrakis A, Velimezis G, Kapogiannatos G et al (2012) Spigel hernia: a single center experience in a rare hernia entity. Hernia. https://doi.org/10.1007/s10029-012-0925-2

30. Skouras C, Purkayastha S, Jiao L, Tekkis P, Darzi A, Zacharakis E (2011) Laparoscopic management of spigelian hernias. In Surgical Laparoscopy, Endoscopy and Percutaneous Techniques 21(2):76-81. https://doi.org/10.1097/SLE.0b013e31820d66df

31. Moreno-Egea A, Campillo-Soto Á, Morales-Cuenca G (2015) Which should be the gold standard laparoscopic technique for handling Spigelian hernias? Surg Endosc. https://doi.org/10.1007/ s00464-014-3738-9

32. Carter JE, Mizes C (1992) Laparoscopic diagnosis and repair of spigelian hernia: report of a case and technique. Am J Obstet Gynecol 167:77-78. https://doi.org/10.1016/s0002-9378(11) 91630-5

33. Zuvela M, Milicevic M, Galun D et al (2013) Spigelian hernia repair as a day-case procedure. Hernia. https://doi.org/10.1007/ s10029-012-1002-6

34. Rankin A, Kostusiak M, Sokker A (2019) Spigelian hernia: case series and review of the literature. Visc Med. https://doi.org/10. $1159 / 000494280$

35. Huber N, Paschke S, Henne-Bruns D, Brockschmidt C (2013) Laparoscopic intraperitoneal mesh fixation with fibrin sealant of a Spigelian hernia. GMS Interdiscip Plast Reconstr Surg DGPW. https://doi.org/10.3205/iprs000028

36. Jamshidian M, Stanek S, Sferra J, Jamil T (2018) Robotic repair of symptomatic Spigelian hernias: a series of three cases and surgical technique review. J Robot Surg. https://doi.org/10.1007/ s11701-017-0742-9

37. Pirolla E, Fregni F, Leme-Godoy A, Schraibman V (2015) A feasibility report of a novel and unpublished surgical approach for Spiegel's hernia: reconstruction using robotics-assisted surgery. Adv Heal Care Technol. https://doi.org/10.2147/ahct.s59791

38. Zeina AR, Mahamid A, Sakran N, Troitsa A (2012) Computed tomographic diagnosis of incarcerated Meckel's diverticulum in a patient with bilateral spigelian hernia. J Gastrointest Surg. https:// doi.org/10.1007/s11605-011-1638-Z

39. Chiu SH, Chang WC, Lin HH, Lee TY (2020) Spigelian hernia of stomach with gastric outlet obstruction. Intern Med. https://doi. org/10.2169/internalmedicine.3752-19

40. Khadka P, Sharma Dhakal SK (2017) Case report of ovary and fallopian tube as content of a Spigelian hernia-a rare entity. Int J Surg Case Rep. https://doi.org/10.1016/j.ijscr.2017.01.015

41. Kuzan TY, Kuzan BN, Sadıkoğlu B, Tüney D (2019) Spigelian hernia including the urinary bladder: a rare potential cause of surgical complication. J Radiol Case Rep. https://doi.org/10.3941/ jrcr.v13i3.3490.PMID:31565172

Publisher's Note Springer Nature remains neutral with regard to jurisdictional claims in published maps and institutional affiliations. 